\title{
Managing NASA's International Space Station Logistics and Maintenance Program
}

\author{
Anthony J. Butina \\ Johnson Space Center, Houston TX 77059 (281) 286-2578, tbutina@ems.jsc.nasa.gov
}

\begin{abstract}
The International Space Station's Logistics and Maintenance program has had to develop new technologies and a management approach for both space and ground operations. The ISS will be a permanently manned orbiting vehicle that has no landing gear, no international borders, and no organizational lines - it is one Station that must be supported by one crew, 24 hours a day, 7 days a week, 365 days a year. It flies partially assembled for a number of years before it is finally completed in 2006 . It has over 6,000 orbital replaceable units (ORU), and spare parts which number into the hundreds of thousands, from 127 major US vendors and 70 major international vendors. From conception to operation, the ISS requires a unique approach in all aspects of development and operations. Today the dream is coming true; hardware is flying and hardware is failing. The system has been put into place to support the Station for both space and ground operations. It started with the basic support concept developed for Department of Defense systems, and then it was tailored for the unique requirements of a manned space vehicle. Space logistics is a new concept that has wide reaching consequences for both space travel and life on Earth. This paper discusses what type of organization has been put into place to support both space and ground operations and discusses each element of that organization. In addition, some of the unique operations approaches this organization has had to develop is discussed.
\end{abstract}

\section{INTRODUCTION}

The International Space Station will be a permanently manned orbiting vehicle that has no landing gear, no international borders, and no organizational lines. It will be one Station that must be supported by one crew, 24 hours a day, 7 days a week, 365 days a year. It flies partially assembled for a number of years until completely assembled in April of 2006. Manned space logistics is a new concept that will have wide reaching consequences for both space travel and life on Earth.

The purpose of the International Space Station is to perform science in an environment like no other on earth. An environment where gravity is measured in micro gravitational units. Where solids, liquids and gases do things that they can't do on earth. I believe that it also fulfills a basic human need to explore. We cannot all be astronauts, but by being a part of this program we can all feel like explorers. Humans have been seekers of the unknown. What is across that stretch of land, that body of water and out there beyond those stars? From one continent to another we roamed, when we came to the sea we developed ships to transport us across the oceans. These people became known as seafarers. In the last 35 years we have started to become a world of spacefarers. We have begun to move out into that vast body of the unknown we call outer space. Now not as one nation, but as a multitude of nations with one common goal - to build and support an international permanently inhabited outpost in space. Something the world has never done before.

Everyday we blaze new and unproven paths for space travel. Engineers, designers, and manufacturers develop equipment that will support life 200 miles above the earth. Electrical systems, fluid systems, electronic and mechanical systems must work in perfect harmony in a hostile and unfriendly environment with equipment and hardware that will fail and need to be repaired.

From conception to operation, the International Space Station requires a unique approach in all aspects of development and operation. Today the dream is coming true; hardware is flying and hardware is failing. A logistics and maintenance system has been put into place to support the International Station. 
The following is the ISS L\&M Organizational Objective and Mission Statement. It has been our main guidance for the past six years:

\section{Objective}

To define, procure, deliver and manage the resources required to support and maintain ISS systems and support equipment both on-orbit and on the ground.

\section{Mission Statement}

During Design and Development Phase: Define necessary supportability requirements. Ensure they are planned for and met, and that all the necessary products are developed economically and on time to support safe and successful operations.

During The Operations Phase: Manage logistics resources and conduct maintenance operations that ensure that the on-orbit vehicle and it's associated systems support safe, successful operations and utilization.

\section{ORGANIZATIONAL STRUCTURE}

\section{Logistics Engineering}

Today, the Logistics Organization has evolved for ISS as shown in Figure 1. This structure has two, what one might call, traditional ILS sections - Logistics Engineering and Supply Support. Logistics Engineering is responsible for Logistics Support Analysis, oversight of the Logistics Support Analysis Records database, and the Logistics technical data and documentation development and delivery. In addition to evaluating change requests and performing repair level analysis, the Logistics Engineering section is also responsible for ensuring that all data coming from the various hardware providers is uniform and is integrated properly. This is not an easy task. In addition to the Prime hardware provider, Boeing with its three major development sites, there is Government Furnished Equipment to be integrated along with data from the International Partners. The total ORU count today is 6,000 units. It is estimated that there will be over 300,000 to 500,000 line items at the end of the program. Instructional documentation has been developed and distributed to all hardware providers to ensure uniformity. Recently, the program changed from the older Mil-Std-1388.2A hierarchical database system, to the Mil-Std1388.2B relational database. This gives us more flexibility, and provides enhancements for the ultimate customer in the Mission Operations Directorate.

\section{Supply Support}

During the development phase the Supply Support Section is primarily responsible for spare parts procurement and management. In the sparing world a short and low quantity production run program has many difficulties to overcome. There is no long production line to procure spares from. There are limited quantities of manufacturing excess parts. Suppliers and manufacturers are not around for a long time to procure parts. There is a very limited amount of historical data available from other programs. For example, Skylab was designed to operate for a very limited time, and used multiple level of redundancy to handle failures. Because of the short development time, test data was not available to validate predicated failure rates. Due to the cut back in Department of Defense programs there are now limited amounts of parts and vendors from which to procure highly reliable parts. Most manufactures and developers are currently in the process of changing over to commercial programs. And, of course, the cost was a major factor. Early in the program it was estimated that spare and repair parts would exceed 1 billion dollars. A figure that not many people wanted to hear. Today we are at an estimated cost of $\$ 750$ million for spares, with a moderate amount of risk to the program. With additional data being developed the one billion dollar estimate may become a reality. In addition, there was no system availability goal to use as a standard. Decisions needed to be made early with this limited amount of information. 
ISS Operations

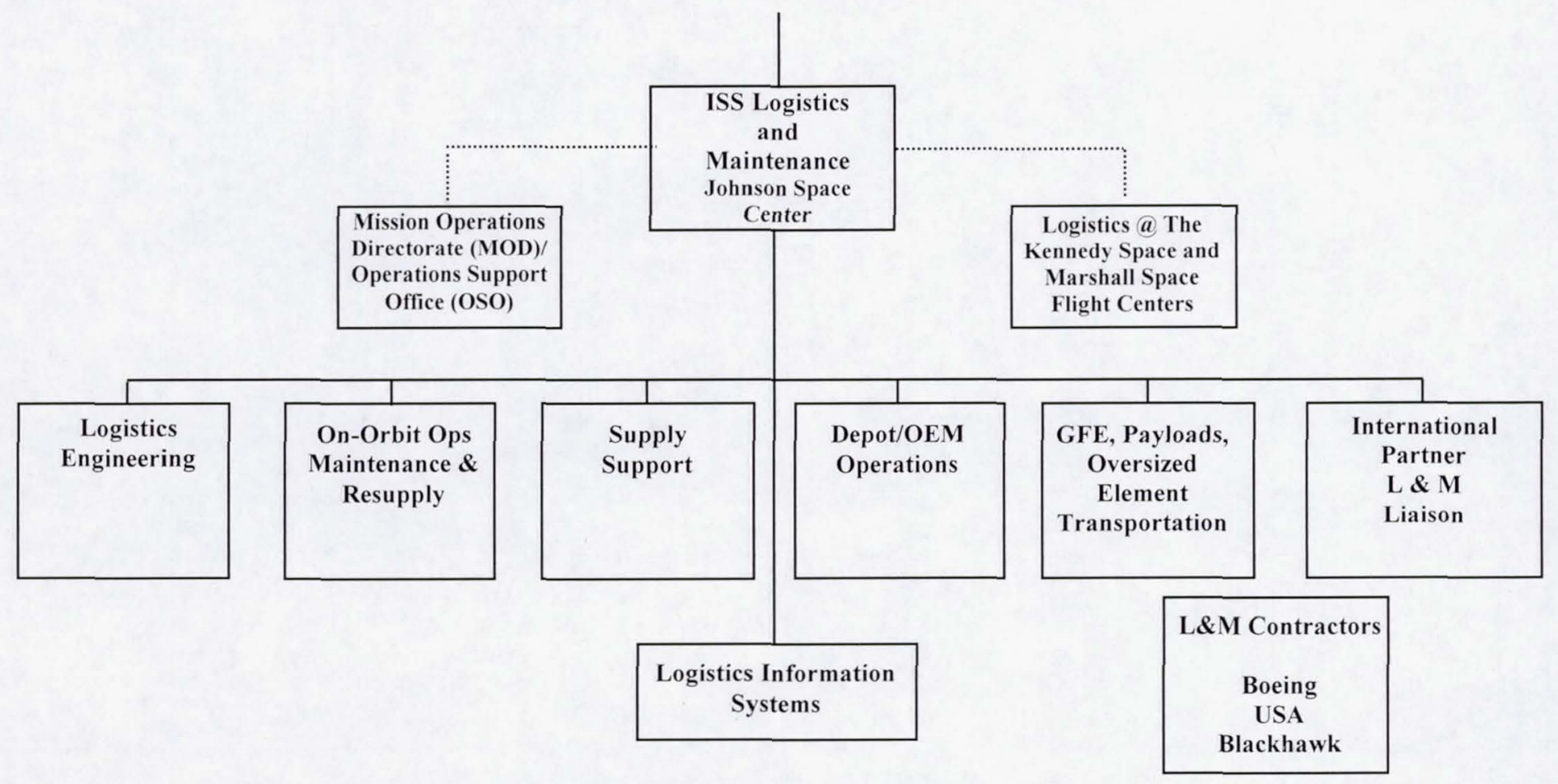

FIGURE 1. ISS L\&M Program Office Organizational Chart.

We decided early that we would put off as long as we could the procurement of spares, but that we would order prior to the close of the production lines. Spares Acquisition Integrated with Production (SAIP), was our goal. Doing this, we believed, would save us large amounts of money in production line re-start costs. In most cases we were able to order parts as part of the manufacturing process, knowing the risk of parts becoming obsolescent or the need for redesign. Today this has paid off. There have only been a few cases of obsolescent parts and the need for redesign.

With the limited amount of data available the decision was made to use the predicted Mean Time Between Failure as the starting point for spares analysis. Ground rules were developed and approved by management. We would use any data available from engineering and test. We would work closely and consult with engineering prior to any ordering of spares. Each subsystem manager was contacted and made part of the ordering decision. Criticality of the system would be considered, but would not be the sole reason to order or not to order.

The following were the groundrules and assumptions established early in the program, and are still valid today:

- The purpose of maintenance is to keep items in, or restore them to, a specified operational condition.

- There are two levels of on-orbit maintenance:

- Organizational - Consists of removal and replacement of ORUs, in-situ repair, servicing and manual fault isolation. Conducted IVA, EVA and EVR.

- Intermediate - Consists of removal and replacement of SRUs at a Maintenance Work Area, light repair of cables and connectors, and the application of authorized repair kits. Conducted IVA only. Upmass is considered a Program resource. Maintenance planning will include minimizing upmass.

- Crewtime is considered a Program resource. Maintenance planning will include minimizing crewtime, especially EVA crewtime.

- Up to five racks of internal stowage volume is available for spares by Assembly Complete. The period of support is First Element Launch through Assembly Complete plus ten years (per the System Specification)

- All aspects of the design are considered necessary, or they would not have been incorporated in the first place. Therefore, leaving an item failed permanently is not an aspect of the maintenance concept. 